\title{
La casa verde de Mario Vargas Llosa
}

Tuestras novelas eran bastante simples hasta que el siglo $\mathrm{xx}$ nos 1 trajo la pampa barrida por nuevos usos, la selva en pugna con nuevos principios económicos, la barbarie del llano contra fórmulas de avance. Pero las novelas del conocido triángulo-Gallegos, Güiraldes, Rivera-son arquetipos, conscientes de su propósito y mensaje, tan preocupadas con los símbolos como con la caracterización de sus personajes. Treinta años de dos guerras, desengaños, potencias que pasan a ser islas subsidiarias, existencialismo, ciudades enclaustradas por plagas indefinibles $y$, al fin, el descubrimiento de que los grandes problemas humanos son universales y que el hambre y la miseria van desde las márgenes más oscuras del Amazonas hasta las viviendas piojosas de Watts. Ahora sabemos bastante antropología para reconocer que no hay un país perfecto, que el poder es relativo, que todos nos vamos a ahogar en el mismo torbellino de sucias aguas atómicas o en el mismo gran dilema de ser o de existir. Ahora se pueden escribir novelas hispanoamericanas sin necesidad de justificaciones o de llamadas a las armas. Se puede seguir el camino trazado por los tres grandes maestros sin recurrir a la obvia y a veces muy objetable propaganda política.

En nuestras tres novelas clásicas - Doña Bárbara, Don Segundo Sombra y La vorágine- se sobreponen y articulan las pesadillas cálidas de la naturaleza o el caciquismo. Hay en ellas remansos de ensueño y torbellinos de violencia, fe ingenua, cierto quijotismo gauchesco, mujeres aceradas, un hombre perdido en la selva, ríos, llanos y hasta una vislumbre del mar. Todos estos factores se entretejen en $L a$ casa verde y a ellos se ha añadido una presencia concreta y zigzagueante, la del río. Un río americano, largo, lento y traicionero, una serpiente enemiga que impasiblemente e irremisiblemente trae y lleva mercancías, viajeros, la ley y la destrucción.

Esta comparación o integración de tres novelas en una no es ni gratuita ni forzada, y es muy probable que haya sido el propósito definido del autor. Es preciso recordar que la autoconciencia del novelista 
es una aportación del siglo $\mathrm{xx}$ y que el fenómeno no aparece en la novela anterior. Una novela actual no se puede enfocar con las mismas armas críticas con que estudiamos Los hermanos Karamazov, porque si bien Dostoievsky conocía intuitivamente los arquitrabes de la novela, no tenía el sentido de forma que se requiere del autor contemporáneo. Decir que Vargas Llosa ha consolidado tres intenciones no es restarle mérito; por el contrario, implica señalar que enfoca la novela no sólo como arte sino también como arquitectura.

La cascs verde comienza con una escena vagamente recordatoria de Doña Bärbara. Una geografía parecida, otros personajes, otros problemas, otra escuela literaria, pero el mismo choque entre la naturaleza y los hombres; el aire de ilusión es común, aunque separado por unos cuarenta años de rápida evolución técnica. $Y$ en lugar de Segundo Sombra, la sombra de Fushía, viajero incansable, comido por dentro y por fuera por una civilización mal entendida y mal extendida. $Y$ en la vorágine aplastante de la selva, la huida de los explotados, la organización tentacular de los explotadores. La nota nueva, el símbolo, es la casa verde, una mancha de frescura, de amores imposibles, el sacrificio de una virgen, la alegría exterior y ficticia al margen de un pueblo insensible. La casa verde es una historia de humillaciones, desesperación, pequeñas rebeliones inútiles, la desintegración inevitable de seres y cosas, artefactos y almas, entre "murallas de árboles que exhalan un vaho quemante, pegajoso".

Se siente la tentación de jugar inventando una nueva trilogía y establecer que esta es, con Rayuela, la gran novela hispanoamericana del presente. Para completar el triángulo literario podría usarse $L$ a región más transparente de Carlos Fuentes. Las tres novelas se reúnen en un mismo fondo de desencanto: el sentido de que el universo es caos y que la América española ha recibido una buena tajada de éste, sin ninguna de sus ventajas. Rajuela es la historia de un exasperado superracionalista sin más refugio que un impermeable simbólico. La región mâs tramsparente es el descubrimiento de que Ja "aristocrática esterilidad" del Anáhuac puede ser muy estética, pero es también muy incómoda. La casa verde es más ambiciosa, más compleja, más planeada. Está má cerca de la tierra, de la calle, del barrio, del pueblo, de la montaña, de la selva, de América. "A nadie puede darle vergüenza su tierra", dice Bonifacia, la Selvática, desarraigada en contra de su voluntad. El autor ama a sus personajes, los trata con compasión y ternura, y con ellos puede leer el rastro del escape y de la lucha, escuchar la música de un país que crece y sentir las punzadas de todos los enemigos del hombre americano, 
la arena, la lluvia y el fuego, los animales, las plantas y sobre todo el río, el personaje central del libro.

Pero no se puede analizar una novela a través de puras generalidades. Hay que encontrar su semilla, su corazón. Precisar su punto de vista, viajar con sus personajes, sumergirse en su diseño, medir su espacio, sentir su tiempo. El punto de vista es fácil de hallar: es el del pueblo, no el del autor. Sentimos, más que observamos, el desarrollo de varias vidas, vistas desde abajo, con ese perfil incompleto con que se nos ofrecen los personajes que nos rodean o los episodios de que formamos parte. Hay también dos realidades en la novela, una realidad firme, la del río omnipresente, y una realidad evasiva, la de los hombres en pugna con esa presencia ominosa que apenas logran percibir parcialmente. Los personajes cambian, aman, olvidan, pero siempre por los mismos caminos, en la infinita y circular búsqueda de un pedazo de pan y un poco de paz. En este paisaje la casa verde es un punto de apoyo, una brújula misteriosa que, cuando deja de ser físicamente, continúa como la contramarca de vidas y conciencias.

La caracterización presenta diversos aspectos de la compleja realidad americana: la fe sencilla de las monjas, la ambición de Fushía, la bondad del viejo Aquilino, y el impacto de un sentido occidental de la vida en un grupo cercado por un mundo primitivo e indomable. $Y$ si hay un mensaje, es el de que mientras no se dome esa naturaleza hostil, todas las fórmulas -religión, placer, poder o dinero- están llamadas al fracaso. La tenacidad de los personajes está dirigida hacia un solo propósito: sobrevivir. Los victimarios aparecen levemente; un gesto decide una vida. $\mathrm{La}$ inmensidad de la tierra y el porvenir de sus habitantes. están gobernados por unas cuantas manos ausentes. Obediencia es la única consigna. Sin ella no hay más solución que la cárcel o el éxodo. Tan triste es el porvenir de los indios como el de los blancos. La justicia se queda en las ciudades, refugiada en los titulares de los periódicos. No puede penetrar las turbias aguas de los ríos. Los únicos mensajeros de la civilización que llegan al corazón de esta tierra son la casa verde - el placer pagado-y el ejército. Si hay ambigüedad, es intencional. Es la ambigüedad de la interacción humana, capaz de actuar simultáneamente en diversos planos. Casi puede decirse que el Occidente es manifiestamente estéril cuando se enfrenta a nuestro mundo. La técnica es todavía impotente contra nuestros árboles. Todo lo que puede traer a América es el vicio - la casa verde-, ambiciosos proyectos - Fushía - y una religión ingenua que salva a los indios, o cree salvar- 
los, cortando sus tradiciones. Seguimos colonizando un mundo incolo. nizable, o nada hemos progresado en 400 años.

H1 espacio en la novela es selva y rio; el tiempo es recuerdo y otra vez río. El movimiento es continuo: la barca que lleva a Aquilino y a Fushía se mueve a través de la novela con su cargamento de recuerdos y referencias, a través del río con su cargamento humano destrozado y perseguido. Hay monjas que cuidan a los leprosos y monjas que secuestran a las indias para educarlas. Hay una mujer espléndida que ha tenido hijos con tres hombres y goza de una serena y magnífica inocencia. Todos tienen que escoger entre inacción y desilusión, ser y existir, la inercia, la nada, y el río que se mueve entre vidas estáticas, donde la única ocupación firme es la de esperar. Todas las demás llevan a la destrucción inmediata. Hay violaciones, raptos, escapadas, rebeldías, sensualidad animal y limpia, sensualidad retorcida y sádica, estupor, cárceles, fugas; solamente el río permanece y se mueve, cambia y se marcha. El río es el tiempo, que fluye, que se enrosca; es también el espacio. Y es tácil adivinar el propósito. Vargas Llosa se propuso aquí escribir la novela del interior como antes había escrito la novela de la ciudad.

El tiempo de la novela es a manera del tempo de una composición musical, capaz de adaptarse a la disposición y maneras del intérprete. Este concepto antimecánico del tiempo puede confundir al lector, pero jamás confunde a los personajes. El tiempo no es estricto en cronología sino en interrelaciones y, claro que sin éstas, el tiempo no existiria. Pero en este caso es el lector el que tiene que establecerlas, porque nos hallamos en una novela sin almanaques. El tiempo se siente, se encuentra, pero no sin lucha. Los ejemplos abundan: "sólo años después" (p. 243), "En ese tiempo Alejandro era joven de verdad" (p. 267), "Nos conocimos hace muchísimo tiempo" (p. 275), "encerrado ahí hace meses" ( $p$. $3^{6 r}$ ), "Lo conozco desde antes que tú nacieras". (p. 394), "Yo tenía treinta años entonces" (p. 4ris).

Este concepto del tiempo como responsabilidad del lector hace dificil la novela contemporánea, pero la imprecisión es sólo para nosotros, no para los personajes. Habla alguien: "Me hubiera gustado saber qué edad tiene exactamente. Más de ochenta, seguro. Es mayor que yo, que ya ando por los sesenta". (p. 396). El personaje sabe perfectamente de qué momento, de qué año, de qué día está hablando. También lo saben sus compañeros de diálogo. Ignoran el pasado histórico pero conocen el calendario de sus vidas. El tiempo es relativo, pero el momento del nacimiento es invariable. 
La novela es un círculo. Dentro de éste los personajes se mueven en ondas, condicionados por los ríos. Una frase es una piedra que cae al agua y los hechos y los pensamientos surgen de ella concéntricamente, de un punto a otro, hasta encontrarse de nuevo. Los personajes desaparecen circularmente en la distancia, mientras el río sigue serpenteando. Peto nadie se baña dos veces en el mismo río y uno de los personajes tiene que decir, al final, y en voz baja, "No me acuerdo de nada... Yo era cocinera, pero tampoco me acuerdo", que es casi decir me acuerdo que no me acuerdo. La novela comienza bajo "una sombrilla de jejenes". y termina con el alarido ronco de "una bocina raquítica y desentonada". Se sabe que solamente algo más poderoso que la energía atómica podrả transtormar estos vericuetos del Marañón y sacudir la desesperación de sus gentes. Con los medios presentes no hay esperanza. La casa verde yace en ruina y la novela acaba con el velorio de su dueño. Ya no hay casa verde, pero la selva es indestructible e inconquistable. El cura y el médico, entre tanto, se preparan para asistir al entierro de Anselmo, violador de niñas, amigo de prostitutas, que levantó su casa verde contra las iguanas y los gallinazos y contra los avances del arenal. Ha hecho pintar la casa de un verde esmeralda y escamoso que le da a la novela, construida como película, un toque de tecnicolor. Pero el final es en blanco y negro, mientras hablan el cura y el médico. Casi es decir que en el corazón profundo de las selvas y los ríos lo único que hasta ahora ha alcanzado un algo de permanencia es una religión simple y un poco de ciencia escueta y práctica.

$\mathrm{La}$ arquitectura interna de la Casa verde es zigzagueante y emblemática, $\tan$ lejos de la novelística clásica una catedral de Gaudí coma de las líneas de Brasilia. Hacia atrás de la Casa todo parece convertirse en novela gotıca. No se puede adscribir ni a la línea ni al círculo, es un laberinto premeditado, con delicadezas de encaje pero capaz de rendir su secreto solamente ante la programación de un computer. Los personajes son inventados pero algunos han existido. El autor, según él mismo ha confesado a Luis Harss, conoció al indio Jum y a Fushía. El burdel de Piura es un recuerdo, también sus visitas a la Mangachería. En Santa María de Nieva vio el ciclo enseñanza-alienación a que estaban condenadas las niñas recogidas - con la ayuda de la policía- por las monjas. En 1958 estuvo con los Aguarunas del Marañón. El mismo gobernador, Julio Reátegui, parece ser una versión del Julio Arana, "el rey del oro negro", que mantuvo un ejército y casi un imperio entre los ríos Marañón, Amazonas, Napo y Putumayo a principios del siglo. Los personajes pueden haber existido pero como dice José Miguel Oviedo, "el autor ha interpuesto entre nosotros 
y sus personajes la neblina novelesca de la ambigüedad". Hay personajes, pero cada personaje, cada persona, tiene su máscara. Las vidas - las historias- se entretejen, se cruzan, se apartan, pero cada hilo es parte vital de otro. Bonifacia, un personaje central de la novela, aparece como la niña reacia y brava ante las monjas, como la adolescente enamorada del Sargento Lituma y en Piura es la Selvática de la Casa Verde. Lituma es el sargento simple de Santa María de Nieva pero es el Josefino chulesco de la ciudad. Jum, el cacique torturado por Reátegui, no es sólo la conciencia social de la selva sino también el padre de Bonifacia, arrancada a la tribu para que se cumplan en ella los ritos cristianos de educación, perversión y sacrificio. Es una historia de gentes y de generaciones. El capítulo segundo es el cuadro de crecimiento de un país. El tercero el choque de una nueva generación. Detrás de la historia se sienten los cañonazos de dos guerras.

La novela no se puede reducir a fórmulas conocidas porque es demasiado nueva. No se acomoda a las fórmulas francesas como no-se puede comparar la geografía de América con los campos peinados y pulidos de la bella Francia. Las relaciones entre el caballero Jean Floressas Des Esseintes y el Barón de Charlus con el real Conde de Montesquious son juegos sutiles de retórica comparados con esta masa cálida de gente de la provincia americana. Los juegos de palabras de Joyce, los escolares de Butor, los negros de Faulkner, los entusiasmos pueriles de Hemingway, pertenecen a un mundo aparte, ordenado, en donde las drogas alucinantes todavía no se producian sintéticamente. Vargas Llosa ha explicado su técnica como un regreso a la novela de caballería y ha dicho que la novela, en general, "es una descripción de actos", pero la verdad es más complicada. La casa verde se ha movido del vasto mundo lineal de la lectura, el mundo en que hemos vivido desde la invención de la imprenta, a nuestro mundo condicionado por la técnica, al mundo de la imagen, el mundo del cine. No basta leerla línea a línea, hay que verla. $Y$ aun para entender el estilo de Vargas Llosa es preciso adaptarse a las concepciones wittgensteinianas del lenguaje, el significado no está solamente en el uso, sino en quien lo usa, porque uno de los secretos de Vargas Llosa es el enorme uso y juego del idioma, la posesión absoluta de la palabra. No se puede describir con fórmulas al uso establecidas, porque se trata de una novela que va crear nuevas corrientes y nueva terminología, como Cervantes y Proust crearon las suyas. Se busca en vano una analogía, un ángulo de Marat-Sade, un desplante musical de John Cage, los curiosos análisis orteguianos de Susan Sontag. La novela es todo y algo más. Para interpretarla hay que recurrir a los poetas, al Neruda ide Macchu Picchu: 
Esta fue la morada, este es el sitio aquí los anchos granos del maíz ascendieron y bajaron de nuevo como granizo rojo.

Esperanza Figueroa Amaral.

Elmira College.

New York. 
